\title{
25 Research Square \\ Effects of Dietary Palmitoleic Acid on Vascular Function in Aorta of Diabetic Mice
}

Yasuhiro Takenouchi ( $\square$ takenouchi@med.kawasaki-m.ac.jp )

Kawasaki lka Daigaku

\section{Yoshie Seki}

Josai University: Josai Daigaku

\section{Sachiko Shiba}

Josai University: Josai Daigaku

Kazuo Ohtake

Josai University: Josai Daigaku

Koji Nobe

Showa University: Showa Daigaku

Keizo Kasono

Josai University: Josai Daigaku

\section{Research}

Keywords: diabetes, palmitoleic acid, thoracic aorta, vasoconstriction

Posted Date: November 8th, 2021

DOI: https://doi.org/10.21203/rs.3.rs-1051853/v1

License: (c) (i) This work is licensed under a Creative Commons Attribution 4.0 International License. Read Full License

Version of Record: A version of this preprint was published at BMC Endocrine Disorders on April 18th, 2022. See the published version at https://doi.org/10.1186/s12902-022-01018-2. 


\section{Abstract}

\section{Background}

Chronic hyperglycemia in diabetes causes atherosclerosis and progresses to diabetic macroangiopathy, and can lead to coronary heart disease, myocardial infarction and cerebrovascular disease. Palmitoleic acid (POA) is a product of endogenous lipogenesis and is present in fish and vegetable oil. In human and animal studies, POA is reported as a beneficial fatty acid related to insulin sensitivity and glucose tolerance. However, few studies have reported its effects on aortic function in diabetes. Here, we investigated the effects of POA administration on vascular function in KKAy mice, a model of type 2 diabetes.

\section{Methods}

Male KKAy and C57BL/6J mice at the age of 14 weeks were used in the present study. For each mouse strain, one group was fed with normal diet and the other group was fed POA-containing diet for 2 weeks. Then, the vascular reactivities of prepared aortic rings were measured in an organ bath to determine if POA administration changed vascular function in these mice.

\section{Results}

KKAy mice treated with POA exhibited decreased plasma glucose levels compared with mice treated with normal diet. However, endothelium-dependent vasorelaxant responses to acetylcholine and proteaseactivated receptor 2 activating protein, which are attenuated in the aorta of KKAy mice compared to control C57BL/6J mice under a normal diet, were not affected by a 2-week POA treatment. In addition, assessment of vasoconstriction revealed that the phenylephrine-induced vasoconstrictive response was enhanced in KKAy mice compared to control mice under a normal diet, but no effect was observed in KKAy mice fed a POA-containing diet. In contrast, there was an increase in vasoconstriction in control mice fed the POA-containing diet compared to mice fed a normal diet. Furthermore, the vasoconstriction in aorta in both control and KKAy mice fed a POA-containing diet were further enhanced under hyperglycemic conditions compared to normal glucose conditions in vitro. In the hyperinsulinemic, and hyperinsulinemic combined with hyperglycemic conditions, vasoconstriction was increased in KKAy mice fed with POA.

\section{Conclusion}

These results suggest that POA intake enhances vasoconstriction under hyperglycemic and hyperinsulinemic conditions, which are characteristics of type 2 diabetes, and may contribute to increased vascular complications in diabetes.

\section{Background}


Diabetes mellitus is a chronic metabolic disease that is characterized by elevated levels of blood glucose due to insulin deficiency or (and) insulin resistance. Hyperglycemia in diabetic patients causes vascular abnormalities and progresses to diabetic macroangiopathy, including coronary heart disease, myocardial infarction and cerebrovascular disease [1]. The vascular abnormalities of diabetes mellitus are characterized by endothelial dysfunction and enhanced vasocontractility [2]. Although the therapy for diabetes is performed on the basis of glycemic control, macroangiopathy or neuropathy will frequently proceed accompanied with lower levels of patient quality of life $[3,4]$. Diet remedies, such as dietary restrictions, are important for glycemic control, but it is also necessary to monitor potential dietary composition.

It has been reported that polyunsaturated fatty acids, which are often present in fish and shellfish components, have a favorable effect on many lifestyle-related diseases including diabetes [5]. Many large-scale epidemiological studies have examined the health benefits of fish oil or omega-3 polyunsaturated fatty acids ( $\omega-3$ PUFA) intake for the prevention of cardiovascular diseases $[6,7]$. We have also reported the beneficial effects of fish oil or $\omega-3$ PUFA in in vitro and in vivo studies using type 2 diabetes model animals [8-10]. $\omega-3$ PUFA reduces the risk of cardiovascular disorders by lowering LDL cholesterol levels in serum and has a direct action on aortic endothelial cells $[10,11]$.

In recent years, the monounsaturated fatty acid palmitoleic acid (POA) has also been recognized as an adipocyte-derived lipid hormone (or lipokine) that allows adipose tissue to regulate systemic metabolism, supporting its physiological relevance [7, 12-16]. Circulating POA has three main sources: intake as a natural food, endogenous lipogenesis (cis isomer) and dietary whole-fat dairy products (trans isomer). Both POA isomers have been reported to be associated with lower metabolic risk [12-16]. POA in fish oil and vegetable oil is also expected to increase insulin sensitivity $[12,13]$. We have reported that POA decreased total cholesterol levels in serum and total lipid levels in the liver of high fat diet-fed mice [17]. Although, many studies have reported biological functions for POA, the health benefit of POA intake has not been elucidated. In this study, we investigated the effects of POA intake on diabetes-induced vascular abnormalities using thoracic aortas removed from KKAy mice, a model of type 2 diabetes.

\section{Methods}

\section{Reagents}

Acetylcholine chloride (ACh), phenylephrine hydrochloride (Phe), and Ser-Leu-lle-Gly-Lys-Val-amide (protease-activated receptor 2-activating protein; PAR2-AP) were purchased from Sigma-Aldrich (St Louis, MO, USA). Sodium nitroprusside dehydrate (SNP) was purchased from FUJIFILM Wako Pure Chemical (Osaka, Japan). cis-9-Hexadecenoic Acid (palmitoleic acid; POA) was purchased from Tokyo Chemistry Industry (Tokyo, Japan). All reagents were dissolved in saline and concentrations are expressed as the final molar concentration in the ex vivo organ bath experiments. 


\section{Experimental Design}

Male KKAy mice, which spontaneously develop obesity and type 2 diabetes [18], and control C57BL/6J mice were obtained from Tokyo Laboratory Animals Science (Tokyo, Japan) at 6 weeks of age and fed a standard pellet diet (CE2; CLEA, Tokyo, Japan) for 8 weeks. Mice were exposed to a 12-h light-dark cycle and maintained at a constant temperature of $22 \pm 2^{\circ} \mathrm{C}$ and humidity of $55 \pm 10 \%$. KKAy and C57BL/6J mice were then divided into 2 groups, respectively. For each mouse strain, one group was fed with normal diet (KKAy-Normal and C57BL-Normal) and the other group was fed with diet containing palmitoleic acid (POA: about $300 \mathrm{mg} / \mathrm{kg}$ body weight; KKAy-POA and C57BL-POA) for 2 weeks. The composition of the diet was prepared based on the AIN93G diet. During the experiment, the composition of POA was prepared according to daily weight fluctuations and food consumption in each mouse. The diet compositions are shown in Table 1. The animal experiments were approved by the Institutional Animal Care and Use Committee of Josai University.

Table 1

\begin{tabular}{|c|c|c|c|}
\hline Ingredients & Normal & POA & \\
\hline Corn starch (g) & 39.7486 & 39.7486 & \\
\hline Casein (g) & 20 & 20 & \\
\hline a-Corn starch (g) & 13.2 & 13.2 & \\
\hline Sucrose (g) & 10 & 10 & \\
\hline Soybean oil (g) & 7 & KKAy 6.807 & C57BL 6.773 \\
\hline Cellulose (g) & 5 & 5 & \\
\hline Mineral mix (g) & 3.5 & 3.5 & \\
\hline Vitamin mix (g) & 1 & 1 & \\
\hline L-Cysteine (g) & 0.3 & 0.3 & \\
\hline Choline bitartrate (g) & 0.25 & 0.25 & \\
\hline tert-Butylhydroquinone (g) & 0.0014 & 0.0014 & \\
\hline Palmitoleic acid (g) & 0 & KKAy 0.193 & ${ }^{C 57 B L} 0.227$ \\
\hline Total(g) & 100 & 100 & \\
\hline
\end{tabular}

\section{Collection Of Plasma And Measurement Of Plasma Parameters}


Mice were decapitated under isoflurane anesthesia, and blood samples were collected in tubes using heparinized funnels. The blood samples were centrifuged $\left(200 \times g\right.$ for $20 \mathrm{~min}$ at $\left.4^{\circ} \mathrm{C}\right)$, and the supernatant plasma stored at $-20^{\circ} \mathrm{C}$ until being assayed. Plasma levels of glucose, triglyceride, $\mathrm{HDL}$ cholesterol, total cholesterol and non-esterified fatty acid (NEFA) were each determined using commercially available enzyme kits (FUJIFILM Wako Pure Chemical). Plasma insulin was measured by enzyme immunoassay (Shibayagi, Gunma, Japan).

\section{Measurement Of Isometric Force}

Aortic vascular function was measured as previously described [19-21]. Briefly, the thoracic aorta was quickly isolated and immersed in oxygenated, modified ice-cold bicarbonate-buffered physiologic salt solution (PSS; containing $137 \mathrm{mM} \mathrm{NaCl}, 4.73 \mathrm{mM} \mathrm{KCl}, 1.2 \mathrm{mM} \mathrm{MgSO}_{4}, 0.025 \mathrm{mM}$ EDTA, $1.2 \mathrm{mM} \mathrm{KH}_{2} \mathrm{PO}_{4}$, $2.5 \mathrm{mM} \mathrm{CaCl}_{2}$, and $11.1 \mathrm{mM}$ glucose). Next, the artery was separated from the surrounding connective tissue and cut into rings of 2-3 mm length under a stereoscopic microscope and suspended in a welloxygenated $\left(95 \% \mathrm{O}_{2}, 5 \% \mathrm{CO}_{2}\right)$ bath containing $10 \mathrm{~mL}$ of PSS at $37^{\circ} \mathrm{C}$. For the vasorelaxation studies, the rings were constricted with an equieffective concentration of prostaglandin $F_{2 a}\left(P F_{2 a}\right)\left(1 \times 10^{-6}-3 \times 10^{-6}\right.$ $\mathrm{mol} / \mathrm{L})$. When the $\mathrm{PGF}_{2 \mathrm{a}^{-i n d u c e d}}$ contraction had reached a plateau level, ACh $\left(10^{-9}-10^{-5} \mathrm{~mol} / \mathrm{L}\right), \mathrm{SNP}$ $\left(10^{-10}-10^{-5} \mathrm{~mol} / \mathrm{L}\right)$ or PAR2-AP $\left(1 \times 10^{-8}-3 \times 10^{-6} \mathrm{~mol} / \mathrm{L}\right)$ was added in a cumulative manner. The evaluation of vasodilatability was expressed as a percentage of the level observed prior to adding PGF $_{2 a}$. The tension generated by the aortic rings was amplified and digitized via a transducer (TB-611T; Nihon Koden, Tokyo, Japan) and recorded and stored using Lab Chart software (ADInstruments, Tokyo, Japan). For the vasoconstriction studies, the aortic rings were contracted by cumulative administration of Phe. After isolating the aorta, as described above, and cut into rings of $1.5-2.0 \mathrm{~mm}$ length, the rings were placed in oxygenated PSS. Next, vascular rings were mounted horizontally onto the microvascular force measurement system. In this vasocontraction study, the normal physiological glucose concentration $(11.1 \mathrm{mM})$ was defined as the normal glucose condition. To understand the direct effects of extracellular glucose accumulation, a high glucose condition was established by pretreating the vascular tissues with high glucose-PSS (22.2 mM glucose in PSS) at $37^{\circ} \mathrm{C}$ for 30 minutes, as previously reported by our laboratory [21]. The obtained change in vascular tension was shown as the generated tension per $1 \mathrm{~mm}$ length of the aortic ring.

\section{Statistical analysis}

All results are expressed as mean \pm standard error of mean (S.E.M.). Numbers of mice and samples analyzed are indicated in the Figure legends and Table. Plasma parameters and body weight were compared by analysis of variance (ANOVA) followed by Tukey's multiple comparisons test. Statistical comparisons of concentration-response curves were performed using two-way ANOVA with Tukey's multiple comparisons test. $\mathrm{P}<0.05$ was considered statistically significant. The statistical analyses were performed using Prism 8 software (GraphPad Software, San Diego, CA, USA). 


\section{Results}

\section{Body weight and food intake}

We measured body weight and food intake after we started feeding with the POA-containing diet. The body weight and food intake of KKAy mice were higher than those of C57BL mice of the same age. There was no difference in the body weight and food intake of the normal diet groups and POA-fed groups in both KKAy and C57BL mice (Fig. 1).

\section{Plasma Parameters}

As shown in Figure 2, non-fasting plasma levels of glucose and insulin were significantly elevated in KKAy diabetic mice compared to age-matched C57BL/6J mice. Administration of the POA-containing diet to KKAy mice for 2 weeks resulted in a significant decrease in plasma glucose levels (Fig. 2A), while plasma levels of insulin did not change compared to normal diet group (Fig. 2B).

\section{Vascular Reactivity}

After precontraction with $\mathrm{PGF}_{2 a}\left(10^{-6}-3 \times 10^{-6} \mathrm{~mol} / \mathrm{L}\right)$, cumulative treatment of $\mathrm{ACh}\left(10^{-9}-10^{-5} \mathrm{~mol} / \mathrm{L}\right)$, PAR2-AP $\left(1 \times 10^{-8}-3 \times 10^{-6} \mathrm{~mol} / \mathrm{L}\right)$ or SNP $\left(10^{-10}-10^{-5} \mathrm{~mol} / \mathrm{L}\right)$ was performed. The ACh- and PAR2-APinduced relaxation of aortic rings isolated from KKAy mice were significantly weaker than those of C57BL/6J mice administered the Normal diet (Fig. 3A, B). The administration of POA for 2 weeks had no effect on the vasorelaxant response in both the KKAy and C57BL/6J groups. The relaxation induced by the direct NO donor SNP showed no significant difference between C57BL-Normal and KKAy-Normal (Fig. 3C). However, the relaxation induced by SNP in aorta from KKAy mice administered POA-containing diet was attenuated compared with those from C57BL mice treated with Normal and POA diet (Fig. 3C).

We then examined vascular contractile responses caused by Phe, which stimulates $a_{1}$-adrenergic receptors (Figs. 4 and 5). Phe-induced vasocontraction in the aorta from KKAy-Normal mice was significantly greater than in C57BL-Normal mice. In the aorta from POA-administered mice, the vasoconstrictive response was enhanced in C57BL mice, but no change was observed in KKAy mice (Fig. 4). Next, the effect of direct treatment with extracellular glucose or/and insulin concentration on Pheinduced aortic contractile responses was examined (Fig. 5). The high glucose condition (HG) was performed by treating the tissue for 30 minutes in PSS containing $22.2 \mathrm{mmol} / \mathrm{L}$ glucose, which is double the normal glucose levels (NG; $11.1 \mathrm{mmol} / \mathrm{L}$ ), a condition that models transient postprandial hyperglycemia. In high glucose-PSS-treated aorta isolated from C57BL-Normal mice, only a slight increase in contraction was observed when Phe was added at $3 \times 10^{-7} \mathrm{~mol} / \mathrm{L}$ or higher (Fig. 5A). The aortas from the other groups showed high vasocontraction in HG compared with NG (Fig. 5B-D). Comparing Phe-induced vasoconstriction in the aorta from C57BL and KKAy mice under high glucose conditions, the aorta of POA-fed mice showed increased constriction compared to the aorta of mice fed a 
normal diet (Fig. 5A-D). Similarly, Phe stimulation was performed in the presence of $10 \mathrm{nmol} / \mathrm{L}$ insulin to model a condition that is comparable to postprandial hyperinsulinemia. In the high insulin condition (HI), the vasoconstriction responses of the aorta from C57BL-Normal, -POA and KKAy-Normal mice were not affected, but the response of the aorta from KKAy-POA mice showed a significant increase in tension (Fig. 5B-D). The Phe-induced vasoconstrictive response under high glucose and high insulin conditions also showed the same results as in the high insulin conditions (Fig. 5B-D).

\section{Discussion}

The results of the present study showed that chronic dietary POA supplementation enhances vasoconstrictive responses under high glucose and insulin conditions in aorta from KKAy diabetic mice.

To determine the composition of the diet to be administered, we measured body weight and food intake after 8 weeks on a normal diet. Body weights and food intakes were $25.1 \pm 0.3 \mathrm{~g}, 3.3 \pm 0.05 \mathrm{~g} / \mathrm{day}$ (C57BL) and $39.9 \pm 0.5 \mathrm{~g}, 6.2 \pm 0.1 \mathrm{~g} /$ day (KKAy), respectively. Based on this data, the composition of the diets for the C57BL and KKAy mice was prepared as shown in Table 1. Changes in body weight and food intake were obtained during the 2 weeks of POA administration, as shown in Figure 1; however, body weights remained largely unchanged during the treatment period for both the C57BL and KKAy mice. This indicates that the mice in each experimental group consumed about $300 \mathrm{mg} / \mathrm{kg} /$ day POA. The dosage was chosen based on reports of improved glucose uptake at this dose [22]. After the C57BL and KKAy mice were fed the experimental diets for 2 weeks, plasma parameters for all mice were measured. As shown in Figure 2, insulin levels were not changed by POA treatment, whereas a decrease in glucose levels was observed in the plasma from KKAy mice. Our observations are consistent with reports that POA improves insulin sensitivity $[12,23]$.

Since it has been reported that endothelial-derived NO production decreases under diabetic conditions and vascular tissue becomes chronically insufficiently relaxed [24], we measured endothelium-dependent vasorelaxation. To measure endothelium-dependent vasorelaxation, we used ACh and PAR2-AP, which cause NO-mediated vasodilation in the artery $[25,26]$. It has been reported that these vasorelaxant responses are impaired under diabetic conditions $[27,28]$. Our results also showed that the endotheliumdependent vasodilation by ACh and PAR2-AP were attenuated in aorta from KKAy mice (Fig. 3A, B). On the other hand, the cumulative relaxation response of the NO donor SNP was unchanged in aorta from KKAy-Normal and C57BL-Normal mice. However, the SNP-induced vasodilation in aorta from KKAy-POA mice was attenuated compared with the C57BL-Normal and -POA mice. These results indicate that KKAy mice exhibit endothelial dysfunction, and that NO sensitivity in the aorta is also reduced when POA was administered. Because plasma glucose levels are significantly reduced following 2 weeks of POA administration in KKAy mice, we expected an improvement in endothelial function in KKAy-POA. However, endothelial dysfunction in KKAy-Normal mice did not improve following POA administration. Although we have reported on several substances that alter endothelial function in the absence of decreased plasma glucose levels [10, 20,29], POA may not improve endothelial function despite its ability to decrease blood glucose levels. On the other hand, POA-induced changes were observed in the aortic contractile response 
(Figs. 4 and 5). The Phe-induced contractile response in aorta from KKAy mice reported in this study was enhanced compared with C57BL mice. It is thought that more pronounced vasoconstriction occurs in diabetic conditions due to an increase in contractile ability combined with a decrease in relaxation ability. Although POA treatment of KKAy diabetic mice for 2 weeks did not change the Phe-induced vasoconstrictive response, enhanced aortic contraction was observed in C57BL mice after POA administration (Fig. 4). Such elevated aortic contractility is expected to contribute to vascular disorders including coronary artery disease and stroke [30]. In addition, enhanced vasoconstriction in the aorta of C57BL-POA, KKAy-Normal and KKAy-POA mice resulted in further increases under high glucose conditions in vitro (Fig. 5B-D). When vascular tension is measured under conditions of high glucose concentration, it is known that arterial contractile responses are significantly increased in diabetes [31]. Activation of the Rho kinase pathway induces enhanced vasoconstrictive responses in vascular smooth muscle in diabetic model animals [32]. It has also been reported that activated PKC and ERK1/2 signals induce the proliferation of vascular smooth muscle cells leading to increased vasoconstrictive responses in high glucose conditions in vitro [33]. We observed the direct effects of insulin on ex vivo contractility and found that a high-insulin condition alone had no effect on vasoconstriction in aorta from C57BLNormal and -POA (Fig. 5A, B) mice. In contrast, the Phe-induced vasoconstrictive response in aorta from KKAy mice showed a tendency to be enhanced compared to the normal diet fed mice $(p=0.07)$, and significantly enhanced contraction was observed in the POA diet fed KKAy mice (Fig. 5C, D).

Although the effect of insulin on the response of vascular smooth muscle is not well understood, it is known that insulin treatment promotes the proliferation of vascular smooth muscle cells [34]. In our examinations, only $30 \mathrm{~min}$ insulin administration enhanced the contractile responses of aorta in KKAyNormal and-POA mice. The vasoconstrictive response in both the high glucose and insulin conditions were similar to those of the high insulin condition alone (Fig. 5). POA administration significantly enhanced the aortic vasoconstrictive responses in both C57BL and KKAy mice under the high glucose condition (Fig. 5B, D). Therefore, it was suggested that POA induces enhanced vasoconstriction. POA is also known as a gap junction inhibitor, and it has been reported that inhibition of gap junctions causes a decrease in blood vessel diameter [35]. The increased vasoconstriction in the aorta of POA-fed mice is consistent with this report, however, further investigation is needed. In a clinical study, higher circulating POA in metabolic syndrome was found to be related to cardiometabolic risk [36].

\section{Conclusions}

Although previous studies showed that POA treatment of diabetes mellitus has the beneficial effect of lowering blood glucose or lipid levels, it has also been shown to increase vasoconstriction, especially under the high glucose and high insulin conditions in this study. Thus, ingestion of high amounts of POA may contribute to increased vascular complications in poorly-controlled diabetes.

\section{Abbreviations}

ACh 
Acetylcholine chloride

ANOVA

Analysis of variance

HG

High glucose condition

$\mathrm{HI}$

High insulin condition

NEFA

Non-esterified fatty acid

NG

Normal glucose

PAR2-AP

Potease-activated receptor 2-activating protein

$\mathrm{PGF}_{2 \mathrm{a}}$

Prostaglandin $\mathrm{F}_{2 \mathrm{a}}$

POA

Palmitoleic acid

PSS

Physiologic salt solution

Phe

phenylephrine

S.E.M.

Standard error of mean

SNP

Sodium nitroprusside dehydrate

$\omega-3$ PUFA

omega-3 polyunsaturated fatty acids

\section{Declarations}

\section{Acknowledgements}

The authors would also like to thank FORTE for their language review of the manuscript.

\section{Ethics approval and consent to participate}

All experiments were performed in accordance with the Guidelines for the Institutional Animal Care and Use Committee of Josai University.

\section{Consent for publication}

Not applicable. 
Availability of data and material

All data generated or analyzed during this study are included in this published article.

\section{Funding}

This work was partly supported by JSPS KAKENHI Grant Numbers JP26350904 and 19K11731.

\section{Author Contributions}

Y.T. designed and performed the experiments, analyzed the data, interpreted the results, and wrote the manuscript. Y.S. performed the experiments, analyzed the data and interpreted the results. S.S., K.O. and K.N. analyzed the data and interpreted the results. K.K. designed the experiments, interpreted the results, and wrote the manuscript. All authors read and approved the final manuscript.

\section{Conflicts of interest}

The authors have no conflicts of interest to declare.

\section{References}

1. Stehouwer CD, Lambert J, Donker AJ, van Hinsbergh VW: Endothelial dysfunction and pathogenesis of diabetic angiopathy. Cardiovasc Res 1997, 34:55-68.

2. Y. Shi, P.M. Vanhoutte: Macro- and microvascular endothelial dysfunction in diabetes. J Diabetes 2017, 9:434-449.

3. Bogdanov VY, Osterud B: Cardiovascular complications of diabetes mellitus: The Tissue Factor perspective. Thromb Res 2010, 125:112-118.

4. Wilmot EG, Edwardson CL, Achana FA, Davies MJ, Gorely T, Gray LJ, Khunti K, Yates T, Biddle SJ: Sedentary time in adults and the association with diabetes, cardiovascular disease and death: systematic review and meta-analysis. Diabetologia 2012, 55:2895-2905.

5. Poudyal H, Panchal SK, Diwan V, Brown L: Omega-3 fatty acids and metabolic syndrome: effects and emerging mechanisms of action. Prog Lipid Res 2011, 50:372-387.

6. Watanabe Y, Tatsuno I: Prevention of Cardiovascular Events with Omega-3 Polyunsaturated Fatty Acids and the Mechanism Involved. J Atheroscler Thromb 2020,27:183-198.

7. Innes JK, Calder PC: Marine Omega-3 (N-3) Fatty Acids for Cardiovascular Health: An Update for 2020. Int J Mol Sci 2020,21:1362-1382.

8. Wakutsu M, Tsunoda N, Shiba S, Muraki E, Kasono K: Peroxisome proliferator-activated receptors (PPARs)-independent functions of fish oil on glucose and lipid metabolism in diet-induced obese mice. Lipids Health Dis 2010, 9:101-109.

9. Wakutsu M, Tsunoda N, Mochi Y, Numajiri M, Shiba S, Muraki E, Kasono K: Improvement in the highfat diet-induced dyslipidemia and adiponectin levels by fish oil feeding combined with food 
restriction in obese KKAy mice. Biosci Biotechnol Biochem 2012,76:1011-1014.

10. Takenouchi Y, Ohtake K, Nobe K, Kasono K: Eicosapentaenoic acid ethyl ester improves endothelial dysfunction in type 2 diabetic mice. Lipids Health Dis 2018, 17:118

11. Barre DE: The role of consumption of alpha-linolenic, eicosapentaenoic and docosahexaenoic acids in human metabolic syndrome and type 2 diabetes-a mini-review. J Oleo Sci 2007, 56:319-325.

12. Nunes EA, Rafacho A: Implications of Palmitoleic Acid (Palmitoleate) On Glucose Homeostasis, Insulin Resistance and Diabetes. Curr Drug Targets 2017, 18:619-628.

13. Petit JM, Guiu B, Duvillard L, Jooste V, Brindisi MC, Athias A, Bouillet B, Habchi M, Cottet V, Gambert P, et al: Increased erythrocytes $n-3$ and n-6 polyunsaturated fatty acids is significantly associated with a lower prevalence of steatosis in patients with type 2 diabetes. Clin Nutr 2012, 31:520-525.

14. Mozaffarian D, de Oliveira Otto MC, Lemaitre RN, Fretts AM, Hotamisligil G, Tsai MY, Siscovick DS, Nettleton JA: trans-Palmitoleic acid, other dairy fat biomarkers, and incident diabetes: the MultiEthnic Study of Atherosclerosis (MESA). Am J Clin Nutr 2013, 97:854-861.

15. Cao H, Gerhold K, Mayers JR, Wiest MM, Watkins SM, Hotamisligil GS: Identification of a lipokine, a lipid hormone linking adipose tissue to systemic metabolism. Cell 2008, 134:933-944.

16. Frigolet ME, Aguilar GA:The Role of the Novel Lipokine Palmitoleic Acid in Health and Disease. Adv Nutr 2017, 8:173S-181S.

17. Sachiko Shiba, Nobuyo Tsunoda, Masaki Wakutsu, Etsuko Muraki, Mariko Sonoda, Phyllis S Y Tam, Yoko Fujiwara, Shinji Ikemoto, Keizo Kasono: Regulation of lipid metabolism by palmitoleate and eicosapentaenoic acid (EPA) in mice fed a high-fat diet. Biosci Biotechnol Biochem 2011,75:24012403.

18. Trayhurn P, Wang B, Wood IS: Hypoxia in adipose tissue: a basis for the dysregulation of tissue function in obesity? Br J Nutr 2008, 100:227-235.

19. Takenouchi Y, Kobayashi T, Matsumoto T, Kamata K: Gender differences in age-related endothelial function in the murine aorta. Atherosclerosis 2009, 206:397-404.

20. Takenouchi Y, Tsuboi K, Ohsuka K, Nobe K, Ohtake K, Okamoto Y, Kasono K: Chronic Treatment with a-Lipoic Acid Improves Endothelium-Dependent Vasorelaxation of Aortas in High-Fat Diet-Fed Mice. Biol Pharm Bull 2019, 42:1456-1463.

21. Nobe K, Takenouchi Y, Kasono K, Hashimoto T, Honda K: Two types of overcontraction are involved in intrarenal artery dysfunction in type II diabetic mouse. J Pharmacol Exp Ther 2014, 351:77-86.

22. Bolsoni-Lopes A, Festuccia WT, Chimin P, Farias TS, Torres-Leal FL, Cruz MM, Andrade PB, Hirabara SM, Lima FB, Alonso-Vale MI: Palmitoleic acid (n-7) increases white adipocytes GLUT4 content and glucose uptake in association with AMPK activation. Lipids Health Dis 2014, 13:199.

23. Tricò D, Mengozzi A, Nesti L, Hatunic M, Gabriel Sanchez R, Konrad T, Lalić K, Lalić NM, Mari A, Natali A, Group E-RS: Circulating palmitoleic acid is an independent determinant of insulin sensitivity, beta cell function and glucose tolerance in non-diabetic individuals: a longitudinal analysis. Diabetologia 2020, 63:206-218. 
24. Sena CM, Pereira AM, Seiça R: Endothelial dysfunction - a major mediator of diabetic vascular disease. Biochim Biophys Acta 2013, 1832:2216-2231.

25. al-Ani B, Saifeddine M, Hollenberg MD: Detection of functional receptors for the proteinase-activatedreceptor-2-activating polypeptide, SLIGRL-NH2, in rat vascular and gastric smooth muscle. Can J Physiol Pharmacol 1995, 73:1203-1207.

26. Moncada S: Nitric oxide in the vasculature: physiology and pathophysiology. Ann N Y Acad Sci 1997, 811:60-67; discussion 67-69.

27. Matsumoto T, Kobayashi S, Ando M, Iguchi M, Takayanagi K, Kojima M, Taguchi K, Kobayashi T: Alteration of Vascular Responsiveness to Uridine Adenosine Tetraphosphate in Aortas Isolated from Male Diabetic Otsuka Long-Evans Tokushima Fatty Rats: The Involvement of Prostanoids. Int J Mol Sci 2017, 18.

28. El-Daly M, Pulakazhi Venu VK, Saifeddine M, Mihara K, Kang S, Fedak PWM, Alston LA, Hirota SA, Ding H, Triggle CR, Hollenberg MD: Hyperglycaemic impairment of PAR2-mediated vasodilation: Prevention by inhibition of aortic endothelial sodium-glucose-co-Transporter-2 and minimizing oxidative stress. Vascul Pharmacol 2018, 109:56-71.

29. Takenouchi Y, Kobayashi T, Matsumoto T, Kamata K: Possible involvement of Akt activity in endothelial dysfunction in type 2 diabetic mice. J Pharmacol Sci 2008, 106:600-608.

30. Tardif K, Hertig V, Dumais C, Villeneuve L, Perrault L, Tanguay JF, Calderone A: Nestin downregulation in rat vascular smooth muscle cells represents an early marker of vascular disease in experimental type I diabetes. Cardiovasc Diabetol 2014, 13:119.

31. Nobe K, Nezu Y, Tsumita N, Hashimoto T, Honda K: Intra- and extrarenal arteries exhibit different profiles of contractile responses in high glucose conditions. Br J Pharmacol 2008, 155:1204-1213.

32. Xie Z, Gong MC, Su W, Xie D, Turk J, Guo Z: Role of calcium-independent phospholipase A2beta in high glucose-induced activation of RhoA, Rho kinase, and CPI-17 in cultured vascular smooth muscle cells and vascular smooth muscle hypercontractility in diabetic animals. J Biol Chem 2010, 285:8628-8638.

33. Yang J, Han Y, Sun H, Chen C, He D, Guo J, Yu C, Jiang B, Zhou L, Zeng C: (-)-Epigallocatechin gallate suppresses proliferation of vascular smooth muscle cells induced by high glucose by inhibition of PKC and ERK1/2 signalings. J Agric Food Chem 2011, 59:11483-11490.

34. Shi J, Wang A, Sen S, Wang Y, Kim HJ, Mitts TF, Hinek A: Insulin induces production of new elastin in cultures of human aortic smooth muscle cells. Am J Pathol 2012, 180:715-726.

35. Maibier M, Bintig W, Goede A, Höpfner M, Kuebler WM, Secomb TW, Nitzsche B, Pries AR: Gap junctions regulate vessel diameter in chick chorioallantoic membrane vasculature by both tonedependent and structural mechanisms. Microcirculation 2020, 27:e12590.

36. Merino J, Sala-Vila A, Plana N, Girona J, Vallve JC, Ibarretxe D, Ros E, Ferré R, Heras M, Masana L: Serum palmitoleate acts as a lipokine in subjects at high cardiometabolic risk. Nutr Metab Cardiovasc Dis 2016, 26:261-267. 


\section{Figures}

\section{Figure 1}

Body weight $(A)$ and food intake $(B)$ were measured on days indicated by the symbols. The horizontal axis represents the number of days since the Normal or POA-containing diet was fed to mice. Data are expressed as mean \pm S.E.M. (A) $n=10$ for all groups. (B) $n=3$ for C57BL-Normal and C57BL-POA, $n=10$ for KKAy-Normal and KKAy-POA.

\section{Figure 2}

Plasma glucose (A) and insulin (B) levels in the four experimental groups. Data are expressed as mean \pm S.E.M. of 7-11 mice. ${ }^{\star} P<0.05,{ }^{\star} * \star P<0.001$ (one-way ANOVA with Tukey's multiple comparison test).

\section{Figure 3}

Concentration-response curves following ACh (A), PAR2-AP (B) and SNP (C) treatments of aortic rings. Data are expressed as mean \pm S.E.M. of 6 or 7 mice. ${ }^{* *} \mathrm{P}<0.05,{ }^{* \star *} \mathrm{P}<0.001$ (two-way ANOVA with Tukey's multiple comparison test).

\section{Figure 4}

Concentration-response curves following Phe treatment of aortic rings. Data are expressed as mean \pm S.E.M. of 4 mice. ${ }^{*} \mathrm{P}<0.01,{ }^{\star * \star P} \mathrm{P}<0.001$ (two-way ANOVA with Tukey's multiple comparison test).

\section{Figure 5}

Concentration-response curves following Phe treatments of aortic rings. Organ baths contained normal glucose (NG: $11.1 \mathrm{mM}$ ), high glucose (HG: $22.2 \mathrm{mM}$ ) or high insulin (HI: $10 \mu \mathrm{M})$. Data are expressed as mean \pm S.E.M. of 3-4 mice. ${ }^{\star} P<0.01,{ }^{\star \star *} \mathrm{P}<0.001$ (two-way ANOVA with Tukey's multiple comparison test). 